\title{
Analysis of the performance of a passive hybrid powerplant to power a lightweight unmanned aerial vehicle for a high altitude mission
}

Jordi Renau ${ }^{1}$, Fernando Sánchez ${ }^{1}$, Antonio Lozano $^{2}$, Jorge Barroso ${ }^{2}$, Félix Barreras ${ }^{2, *}$

${ }^{1}$ Univ. CEU Cardenal Herrera. San Bartolomé, 55. 46115 Alfara del Patriarca, Valencia, SPAIN

${ }^{2}$ LIFTEC, CSIC - Univ. Zaragoza. María de Luna, 10. 50018, Zaragoza, SPAIN

\begin{abstract}
The objective of this research is to analyze the performance of a passive hybrid powerplant control system to be implemented in a lightweight unmanned aerial vehicle capable to ascend up to the high troposphere $(10,000 \mathrm{~m})$. The powerplant is based on a high-temperature PEM fuel cell connected in parallel to a set of lithium-polymer batteries and regulated by two power diodes. Test performed in steady state demonstrates that the use of the hybrid system increases the efficiency of the stack by more than $7 \%$ because the voltage at the main DC bus is limited by the batteries. The robustness of the passive control system is proved in a longterm test in which random perturbations of $\pm 15 \%$ are applied to the average power that would be demanded during the ascent flight. The hybridization of the stack with the batteries eliminates sudden peaks in the current generated by the stack, which are responsible for prompt degradation phenomena that drastically reduce its useful lifetime. The study demonstrates that with the passive hybrid powerplant it is possible to reach the target height with the gas storage system considered in the application, contrary to what happens with the simple power plant.
\end{abstract}

Keywords: PEM fuel cell; High-temperature; UAV; LiPo batteries; Passive-hybrid powerplant

${ }^{*}$ Corresponding author: e-mail: felix@litec.csic.es 


\title{
NOMENCLATURE
}

\author{
Acronyms \\ DC Direct current \\ GSS Gas storage system \\ HPP Hybrid powerplant \\ $\mathrm{HPP}_{\mathrm{FC}} \quad$ Power delivered by the stack in the passive hybrid powerplant \\ HPP LiPo Power delivered by the batteries in the passive hybrid powerplant \\ HT-PEMFC High-temperature polymer electrolyte membrane fuel cell \\ ICE Internal combustion engine \\ LiPo Lithium-polymer batteries \\ p-HPP Passive Hybrid powerplant \\ PCB Printed circuit board \\ PWM Pulse-width modulation \\ SPP Simple powerplant \\ UART Universal asynchronous receiver-transmitter \\ UAV Unmanned aerial vehicles
}

\section{Latin letters}

P $\quad$ Power (W)

\section{Greek letters}

$\eta \quad$ Efficiency 


\section{Introduction}

The propulsion system of any aerial vehicle comprises four main parts, namely: the energy source, the storage media, the mechanical energy converter, and the lift/thrust converter [1]. Most of the current unmanned aerial vehicle (UAV) platforms use conventional fuels and internal combustion engines (ICE) because they are developed for the military industry, where a reliable technological maturity is required [2]. In recent years, a growing interest has been focused in the development of UAVs based on fully electric systems due to their low noise level and reduced thermal traceability that are desirable in military applications [3]. However, the most important disadvantage of electrical UAVs is the limitation in flight range.

A solution is to combine different power sources that can be connected either in serial, parallel, or serial-parallel configurations. This strategy is known as hybridization, and its implementation ensures high values of both energy and specific power [4]. The first hybrid powerplants (HPP) were based on ICEs, and achieved a significant reduction in consumption rates $[5,6]$. Hybrid electric control systems can be active or passive. Active systems use energy control and management strategies based on DC/DC converters, while passive ones adjust the voltages of the different power sources at the main DC bus either by direct connection or using power diodes. Active systems usually include control algorithms to recover energy during braking to reduce fuel consumption. They are commonly used in transport applications where weight is not a limiting factor, e.g. in cars, trucks, buses, large yachts, or ships [7-9]. However, even considering the recent advances in electronic miniaturization, the use of heavy inductors that act as filters in the DC/DC converters [10-16] drastically limits the possibility to install active control systems in lightweight UAVs. The principal advantages of passive architectures are the low cost, simplicity, lightweight and reliability, which are very demanded in UAV applications [17]. However, a problem to be solved during the design and selection of the elements of the control system is that the voltages of the different power sources must be equal at the main DC bus. Some authors consider the use of batteries as a simple energy buffer that only ensures the dynamic performance of the powerplant $[18,19]$. Therefore, the specific energy of the HPP is nearly the same to that of the fuel cell, but improving the specific power. The objective of this research is to optimize the operation of the control system of a passive hybrid powerplant ( $p$-HPP) suitable to power a light UAV to ascend up to the high troposphere $(10,000 \mathrm{~m})$. The $\mathrm{p}$-HPP is based on a high-temperature PEM fuel cell (HT-PEMFC) and lithiumpolymer batteries (LiPo) to improve its dynamic performance. To this end, different electronic 
circuits have been designed and manufactured. A commercial Arduino DUE microcontroller is used to control the p-HPP automatically.

\section{Description of the passive hybrid powerplant}

A scheme of the electric layout diagram of the p-HPP considered for this UAV is shown in Fig. 1. It is formed by two power sources, the HT-PEMFC and a set of LiPo batteries, which are common for this purpose due to their high specific energy, which ranges between 170 and 270 $\mathrm{W}-\mathrm{h} \mathrm{kg}^{-1}[20,21]$. In addition to this $\mathrm{p}-\mathrm{HPP}$, the performance of the simple powerplant including only the HT-PEMFC stack (SPP) [22], was also studied. However, there are two main reasons for selecting the hybrid configuration. On the one hand, the presence of the LiPo batteries in the $\mathrm{p}$-HPP ensures the minimum power required to safely recover the UAV if the power delivered by HT-PEMFC suddenly fails. This strategy should be only understood as a controlled descent of the aircraft because, due to weight limitations, the battery pack will never be able to provide the power required to complete the mission. On the second hand, as it will be discussed later, the energy available in the LiPo batteries improves the dynamic performance of the powerplant.

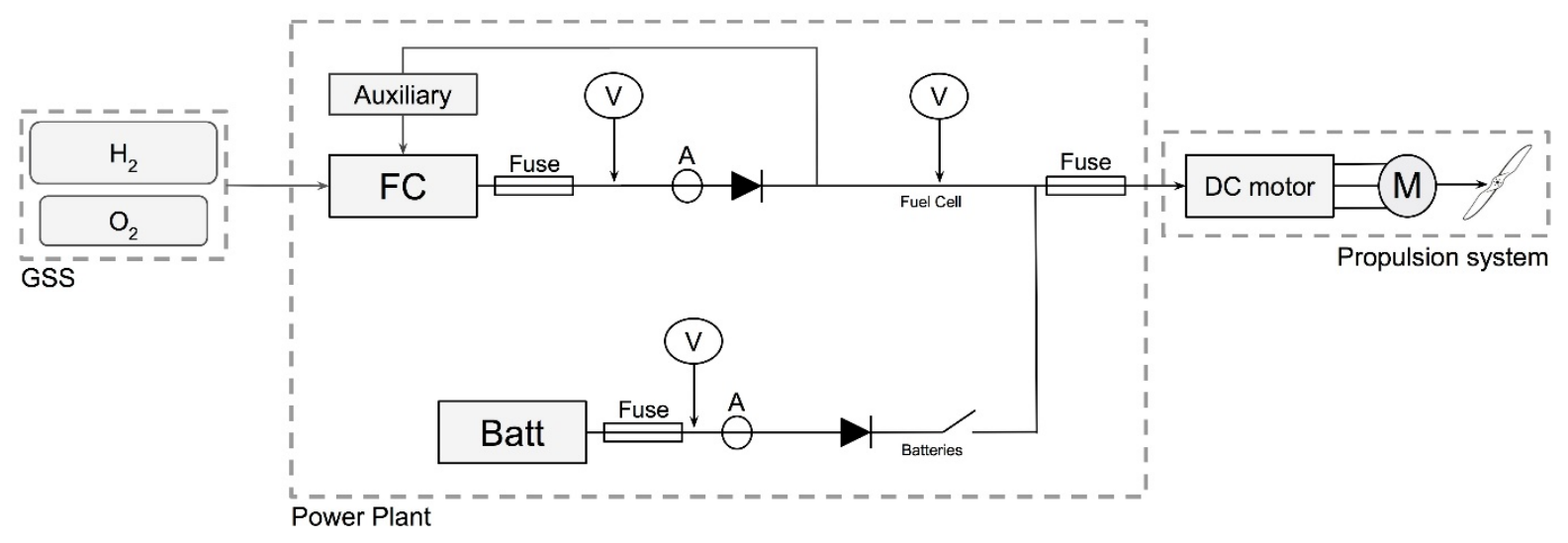

Figure 1: Diagram of electric layout of the passive hybrid powerplant of the UAV

A detailed analysis of the power required by the propeller to ascend at a constant power up to $10,000 \mathrm{~m}$ (high troposphere) was performed in [22], where the main aerodynamic characteristics of the UAV platform can also be found. In summary, for the UAV considered in this project, a power of $422.5 \mathrm{~W}$ has to be supplied to the propeller to complete the highaltitude mission. Therefore, considering an efficiency of the propulsion system (from the DC bus to the propeller) of $68.4 \%$, the minimum power required at the DC bus is $617.7 \mathrm{~W}$. The power can be supplied to the main DC bus from both the HT-PEMFC and the LiPo batteries 
depending on the voltage level at the bus. If all the power is supplied by the HT-PEMFC, the required value increases up to $688.5 \mathrm{~W}$, considering a $10 \%$ of additional losses in the auxiliary systems of the stack, as well as the power needed in its control electronics. On the other hand, if all the power is supplied from the batteries, it would only be of $630.3 \mathrm{~W}$ because of its higher efficiency (98\%), since only the small losses corresponding to the power diode have to be taken into account. A summary of the power required for the three stages of the mission (cruise at sea level, ascent at constant power, and cruise at the target height) is presented in Table 1. It should be noted that the performance of the LiPo batteries is also affected by the electrochemical behavior during the discharge. The faster the discharge is, the lower the battery performance, meaning that less energy can be released.

Table 1: Power (in W) of the different elements of the p-HPP of the UAV

\begin{tabular}{cccc} 
Power (W) & Cruise (at sea level) & Ascending flight & Cruise (at 10 km) \\
\hline Demanded at the propeller: & 165.8 & 422.5 & 285.6 \\
\hline Demanded at the DC bus: & 242.4 & 617.7 & 417.5 \\
\hline Supplied only by the HT-PEMFC: & 255.1 & 686.3 & 439.4 \\
\hline Supplied only by LiPo Batteries: & 247.3 & 630.3 & 426.0 \\
\hline
\end{tabular}

\section{1.- The high-temperature PEMFC stack}

The fuel cell manufactured in this project is a very compact and lightweight stack with Celtec P-1100 high temperature MEAs $[23,24]$ supplied by BASF Fuel Cells with a standard rectangular active area of $81.28 \mathrm{~cm}^{2}$, and an original thickness of $1 \mathrm{~mm}$ (without compression). The operating temperature ranges from $120^{\circ} \mathrm{C}$ to $180^{\circ} \mathrm{C}$, and no humidification for the reactant gases is needed. A detailed description of the characteristics of these MEAs can be consulted in $[25,26]$. In order to work at a low current density, what can enlarge its lifetime, it is formed by 50 cells with monopolar plates manufactured in graphite $(1.5 \mathrm{~mm}$ thick for the anode plates and $2.1 \mathrm{~mm}$ for the cathode ones). With this configuration, the stack is capable of delivering the $686.3 \mathrm{~W}$ demanded by the propeller during the ascending flight with a low current density of $0.28 \mathrm{~A} \mathrm{~cm}^{-2}$. A maximum power of $805 \mathrm{~W}$ is produced for a current density of $0.363 \mathrm{~A} \mathrm{~cm}^{-2}$, and a voltage per cell of 0.503 V. Hydrogen and oxygen Alphagaz 1 with a purity of $99.999 \%$ are used as reactant gases. In order to simplify the system complexity and to limit the total weight of the ancillary systems, reactant gases are supplied at room temperature. Working pressure of hydrogen and oxygen is 0.5 bar. Both gases operate at dead-end mode. The polarization curve of this stack is depicted in Fig. 2 in terms of current density in the horizontal axis, and voltage and power per cell in the vertical ones. As the stack has 50 cells with an active surface of $81.28 \mathrm{~cm}^{2} \mathrm{Fig} .2$ can be easily rescaled to depict the total current, voltage and power 
values. In particular, current should go up to $60 \mathrm{~A}$, total stack voltage corresponds to an interval extending from $15 \mathrm{~V}$ to $50 \mathrm{~V}$, and power ranges between $100 \mathrm{~W}$ and 1,100 W. Dashed lines correspond to the operating point for the maximum power demanded by the DC bus during the ascending flight $(30.6 \mathrm{~V}, 22.5 \mathrm{~A}$, and $686.3 \mathrm{~W})$.

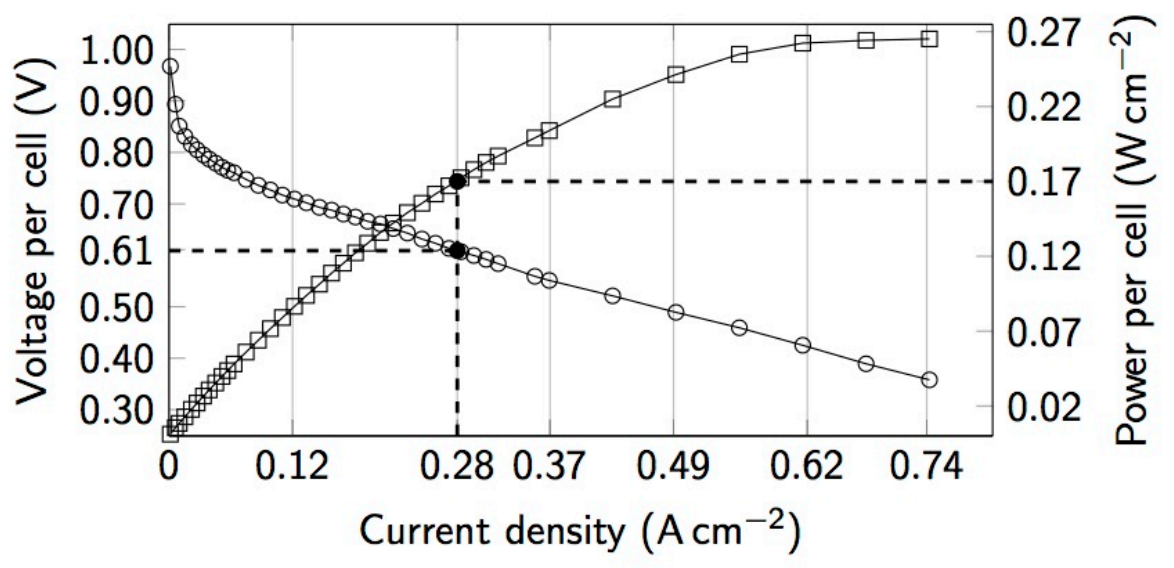

a)

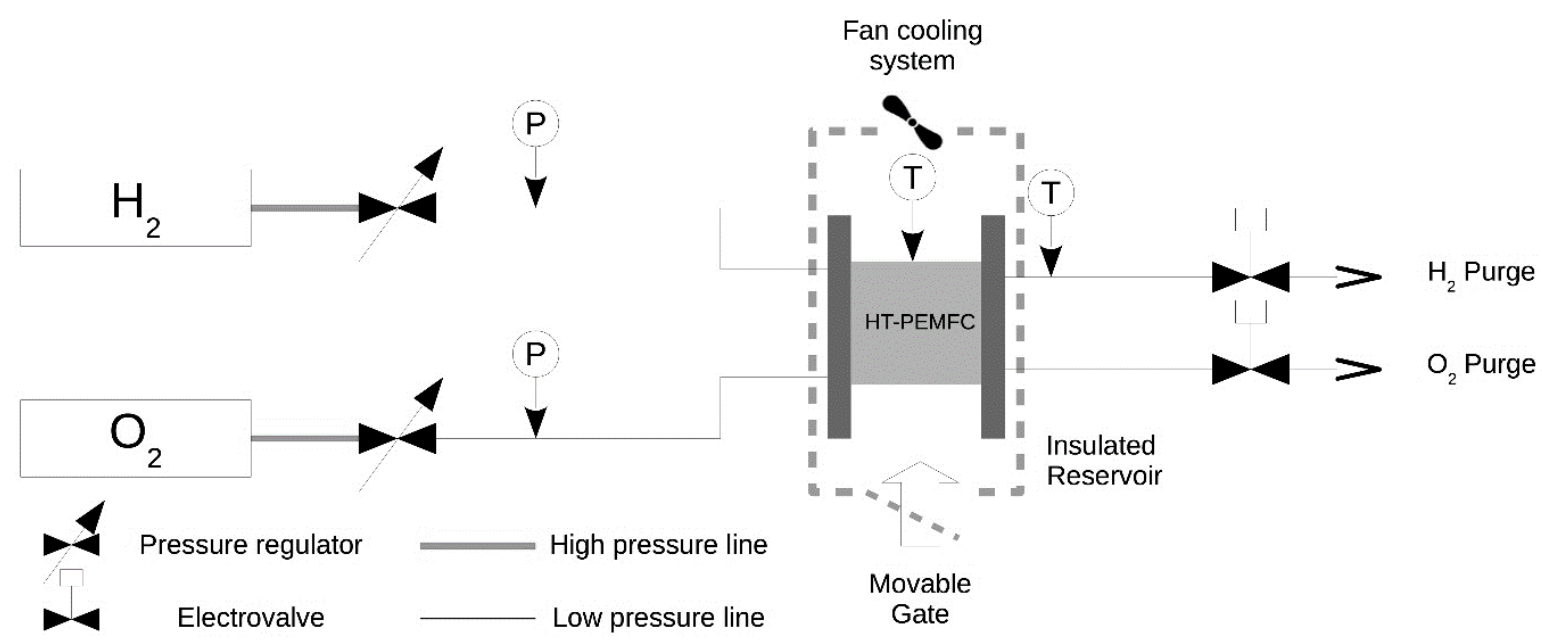

b)

Figure 2. a) Polarization curve of the HT-PEMFC stack; b) flow diagram with the main sensors.

\section{2.- The LiPo batteries}

The LiPo batteries should be as large as possible, only limited by the total weight of the UAV that has to be lower than $16 \mathrm{~kg}$. The weight of the elements forming the different systems is the following,

- Fuselage: 3,512 g (21.9\%)

- HT-PEMFC: $3,873 \mathrm{~g}(24.2 \%)$

- Control electronics: 192 g (1.2\%)

- Gas storage system (GSS): 6,353 g (39.7\%) 
- Electric motor: $570 \mathrm{~g}(3.6 \%)$

- Payload: $150 \mathrm{~g}(0.9 \%)$

which adds up to a total of $14,650 \mathrm{~g}$. Consequently, the maximum weight remaining for the LiPo batteries is $1,350 \mathrm{~g}$, an $8.5 \%$ of the total.

The number of battery cells in serial connection is determined by the total required voltage, which should be compatible with that of the HT-PEMFC. The number of elements in parallel is limited by the total available weight. For this application the battery pack is formed by a single string (1P) of 10 serial LiPo cells (10S). This configuration is identified as 10S1P. The total weight is 1,343 $\mathrm{g}$ and, assuming an average electrochemical discharge efficiency of $95 \%$ and a diode efficiency of $98 \%$, the maximum stored energy is $299.1 \mathrm{~W}$-h, considering a capacity of $8.1 \mathrm{~A}-\mathrm{h}$ and a specific energy of $191 \mathrm{~W}-\mathrm{h} \mathrm{kg}^{-1}$, for a discharge depth of $92 \%$ [27].

\section{3.- The electronic systems}

For these preliminary tests, all circuitries were mounted on prototyping boards, but suitable PCBs will be manufactured to integrate them in the UAV powerplant. The measuring system for all the electrical components is included in the power board, and requires a supply of $5 \mathrm{~V}$ DC. It consists of LTS 25NP Hall effect current sensors, the power diodes for the HT-PEMFC and LiPo batteries, several voltage splitters for voltage measurements, and two connectors, one for the control board and the other to power the measuring electronics.

Two boards, one for each reactant gas, are used in the gas control system. A low-power relay is used to regulate the gas supply valves, and an IRF543 MOSFET transistor is employed to control the purge both in frequency and time duration. The two elements are controlled by a BJT 2N3904BU transistor. To regulate the stack temperature, a cooling system control circuit and a temperature measurement board are required. Once integrated into the UAV, this system requires a proportional output to regulate a sliding cone and movable gates position, to fix the amount of cooling flow surrounding the stack. A complete description of the passive cooling system of this UAV was given in [24]. However, it should be noted that for the experiments performed in the test bench, the real system is simulated with 4 axial fans. To control the air flow moved by the fan system, the stack temperature PWM signal measured with a B57540G1104F thermistor integrated in the HT-PEMFC plates is used. The resistance is directly measured at the main control board by a Wheatstone bridge powered at $3.3 \mathrm{~V}$.

The different electrical parameters are monitored and controlled with an Arduino DUE microcontroller based on the Atmel SAM3X8E ARM Cortex-M3 CPU with a sampling rate of 84 
$\mathrm{MHz}$. This device, which integrates the control of all sensors of the powerplant, is specially designed to be easily incorporated in applications that require flexibility, reliability, and high performance. It has 54 digital input/output pins running at $3.3 \mathrm{~V}$. From those, 12 pins can be used as PWM outputs, while other 12 pins are 12 bytes analog inputs. Among others ports, it also has 4 universal asynchronous receiver-transmitter (UART) hardware serial ports. During the tests, data were acquired in a SD card connected to one of the serial ports. HT-PEMFC stack and LiPo batteries are connected to diodes, ensuring that the current is supplied to the DC bus by the source with the highest available voltage.

\section{Results}

To analyze the performance of the p-HPP, different tests and measurements have been carried out on a test bench. In the experiments, the power demanded by the propeller for the different stages of the flight (see Table 1 ) is simulated by an electronic load. Thus, the DC bus of the p-HPP is connected to a BK Precision IT8514F programmable dynamic electronic load. The resulting values of current and voltage of each element are measured for the different values of demanded power. Both the HPP stationary behavior and its dynamic response were studied, comparing it with a simple powerplant (SPP) with the HT-PEMFC as the only power source. Finally, a long-term test was carried out, in order to investigate the performance of the $\mathrm{p}$-HPP, simulating a 1-hour duration flight. To control the flight conditions during the longterm test, the communication port of the dynamic electronic load was connected to the UAV microcontroller board, where the different curves of the demanded power as a function of time are stored, in order to simulate a real UAV autopilot commander.

\subsection{Steady state performance test}

In this test, the electric performance of each power source (HT-PEMFC stack and LiPo batteries) was analyzed for the different power demanded by the programmable dynamic electronic load at the DC bus. Even when the state-of-charge (from $80 \%$ to 55\%), and hence the voltage (from $38 \mathrm{~V}$ to $35.3 \mathrm{~V}$ ), of the LiPo batteries changed along the test, the term "steady state" is used considering the operating mode of the HT-PEMFC stack. So, sudden changes of the power demanded at the DC bus during this test are avoided, and measurements are performed once the current produced by the stack remains stable for at least 1 minute for each experimental point. Results obtained are depicted in Fig. 3. As can be observed, for currents smaller than 5 $A$, the power to the DC bus is supplied only by the stack. However, the power measured on the DC bus of the P-HPP is a $5 \%$ lower than that delivered by the HT-PEMFC because of the losses 
in the diode. In fact, it was found that voltage losses in the diodes vary as a function of the current, changing from $0.5 \mathrm{~V}$ up to $1.5 \mathrm{~V}$ at the points of maximum demand. When the demanded current reaches $5 \mathrm{~A}$, the voltage of the stack is equal to that of the LiPo batteries, and they start supplying power to the DC bus. From this point, the performance curve of the p-HPP separates from the polarization curve of the HT-PEMFC, maintaining a high voltage despite the increase of the demanded current. However, for currents ranging from $5 \mathrm{~A}$ to 12 A, the behavior of the stack is quite similar to that predicted in Fig. 2a) obtained at the test bench.

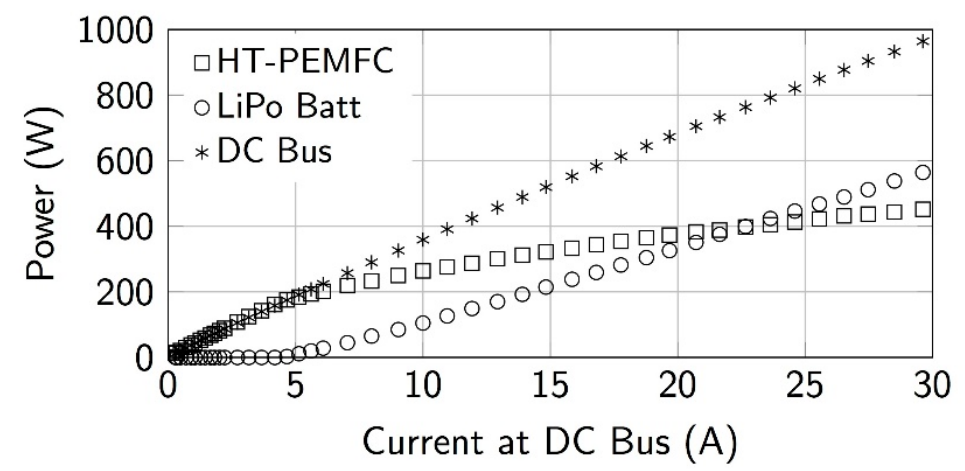

Figure 3: Power curves as a function of the demanded current for the p-HPP

In order to quantify the losses of the power transmission in the cables and in the power diodes, the electronics efficiency and the performance of the stack in the hybrid configuration are calculated. Results are presented in Figs. 4a) and 4b). The values of Fig. 4a) have been calculated using the efficiency of the p-HPP according to the equation,

$$
\eta=\frac{P_{D C \text { bus }}}{P_{\text {stack }}+P_{\text {batt }}}
$$

in which $P$ is the power (in $\mathrm{W}$ ), and the subscripts $D C$ bus, stack y batt refer to the power measured at the DC bus, and those yielded by the HT-PEMFC and LiPo batteries, respectively. In Fig. 4b) the electrochemical performance curve of the HT-PEMFC (dashed line), obtained in the test bench, is compared to the efficiency of the stack for two different cases: the passive HPP, and the SPP where the HT-PEMFC is the only power source. The power of the stack (HTPEMFC) plotted in Fig. 3 is the total generated, part of which is consumed in the ancillary systems (cooling and gas supply systems, and control electronics). At low current loads, the parasitic consumption of these systems is $12 \mathrm{~W}$ resulting in a stack efficiency below $10 \%$. Therefore, the control system should be configured so that, when the demanded current in the DC bus is below $3 \mathrm{~A}$, all the power has to be supplied by the LiPo batteries. This behavior differs from that obtained when performing the polarization curve of the HT-PEMFC without 
considering the actual consumption of the ancillary systems. In this case, the lower the current load, the higher the efficiency (dashed line).

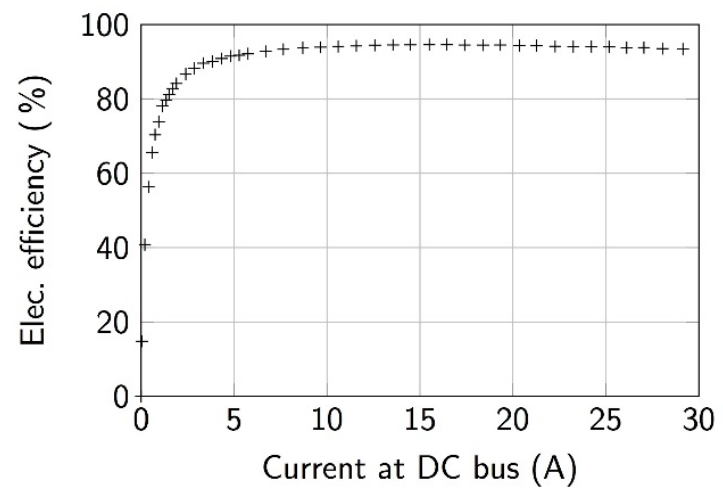

a)

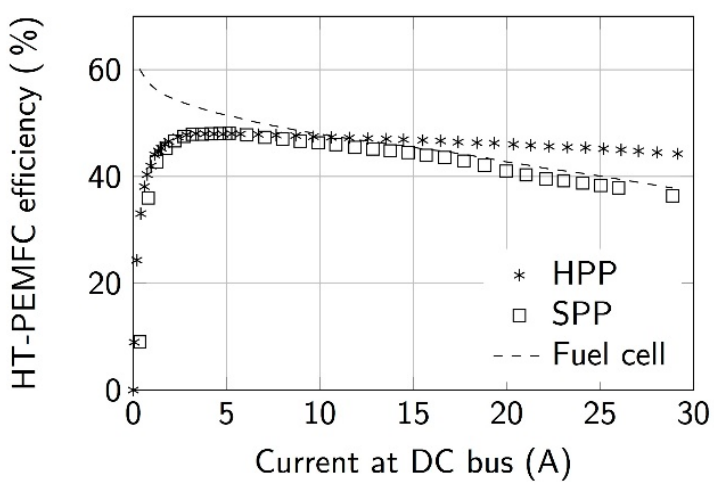

b)

Figure 4: Efficiency of the power transmission stage for the p-HPP (a), and of the stack (b) efficiency

when characterized at the test bench and when working in the hybrid or single powerplants

The maximum efficiency is achieved around 3.2 A, corresponding to a power of $143 \mathrm{~W}$. The parasitic power consumption ranges from $12 \mathrm{~W}$ at low load to $32 \mathrm{~W}$ at maximum stack power. It has been calculated that during the flight, the maximum parasitic power is close to $20 \mathrm{~W}$ due to the low power consumption of the passive cooling system [23]. During the operation in hybrid mode (above $3.2 \mathrm{~A}$ ), the minimum efficiency of the powerplant is $93.4 \%$, obtained for a current of $29.15 \mathrm{~A}$, corresponding to a power load at the DC bus of $948.8 \mathrm{~W}$. At this point, the fuel cell delivers $47.6 \%$ of the total power, with an efficiency of $44.3 \%$. For the SPP, the maximum power generated by the fuel cell is about $800 \mathrm{~W}$ with a conversion efficiency of only $36.4 \%$. At the operating point corresponding to the ascending power (617.7 W on the DC bus), the fuel cell delivers $55 \%$ of the total demanded power, and the batteries the remaining $45 \%$. The effective electrical performance of the p-HPP is $94.5 \%$ and the efficiency of the stack reaches $46.4 \%$. On the contrary, for the SPP, the HT-PEMFC should deliver $675.8 \mathrm{~W}$ because the actual efficiency drops to $91.4 \%$.

\subsection{Dynamic performance test}

Figure 5 shows the curve of the DC bus demanded power as a function of time in order to analyze the dynamic behavior of the two powerplants (SPP and p-HPP).

As the curve is the same for both powerplants, the comparison between the results obtained for each one of them is straightforward. Besides, for the case of the p-HPP, current and voltage were measured in all the different elements for all the power values demanded by the dynamic electronic load. The reaction time of the power and control systems of the real UAV, was simulated with ramps with a duration of $2 \mathrm{~s}$ for power increase, and of $1 \mathrm{~s}$ for decreasing power. 


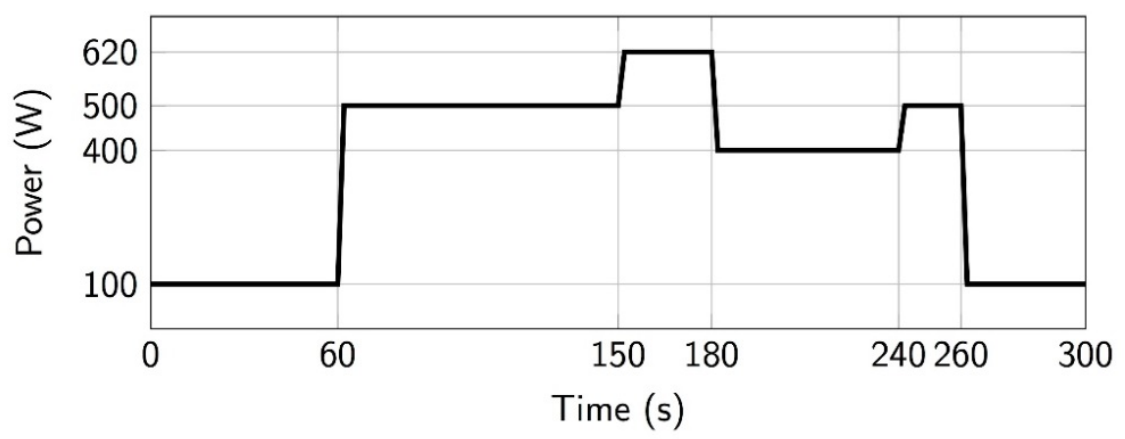

Figure 5: Power curve demanded on the DC bus for the two powerplants

In Fig. 6a) the behavior of the voltage as a function of time for both powerplants is depicted. It should be pointed out that, in the case of the p-HPP, voltages of the two power sources (HTPEMFC and LiPo batteries) are plotted separately, in order to ease the analysis of the role of the LiPo batteries. As can be observed, the initial voltage of the HT-PEMFC is not identical for the two powerplants. For this type of MEAs, manufacturers recommend to start gas supplying after the average temperature of the stack is above $100^{\circ} \mathrm{C}$. To this end, the stack is initially preheated with a thermal blanket electrically powered using the electric network. The resulting initial stack temperature for the SPP was $118^{\circ} \mathrm{C}$, while for the $\mathrm{p}-\mathrm{HPP}$ it was $124^{\circ} \mathrm{C}$. It seems that this small difference in the stack temperature (around $5^{\circ} \mathrm{C}$ ) caused $0.8 \%$ difference in the measured voltage during the first stage. So, in order to optimize the performance of the p-HPP an accurate control of the stack temperature is needed. It was also noted that the stack temperature was homogenized in less than $30 \mathrm{~s}$. The initial voltage of the batteries at the beginning of the test was only $37.2 \mathrm{~V}$, corresponding to a state-of-charge of $68 \%$. It should be noted that the initial SoC of the LiPo batteries affects the performance of the p-HPP. The initial value selected allows to analyze the automatic response of the powerplant to power changes, and ensures that at the low current range the power source that delivers the power demanded by the electronic load is the HT-PEMFC stack.

For the configuration of the SPP, it is observed that a peak power demand on the DC bus (around $\mathrm{t}=60 \mathrm{~s}$ ) causes a sudden voltage drop below $34 \mathrm{~V}$, mainly due to the slow dynamic response of the HT-PEMFC. From $60 \mathrm{~s}$ to $150 \mathrm{~s}$ a constant power is demanded (see Fig. 5), but two different trends can be observed. Up to $90 \mathrm{~s}$ the voltage increases, and then it decreases with almost the same slope (see Fig. 6a). At $150 \mathrm{~s}$ a new increase in power is demanded, which leads to a sudden drop in the measured DC bus voltage. With respect to the current behavior, Fig. 6b) shows a high peak for the SPP, as the power demand is increased, that tends to decrease slowly. The sudden sharp increase of the current demanded to the HT-PEMFC can 
lead to the fast corrosion of the carbon support of the catalyst layers. This is usually caused by global or local gas starvation in either some cells of the stack or in some zones of the electrodes of any cell [28]. This effect is more dangerous in the cathode catalytic layers due to its large potential.

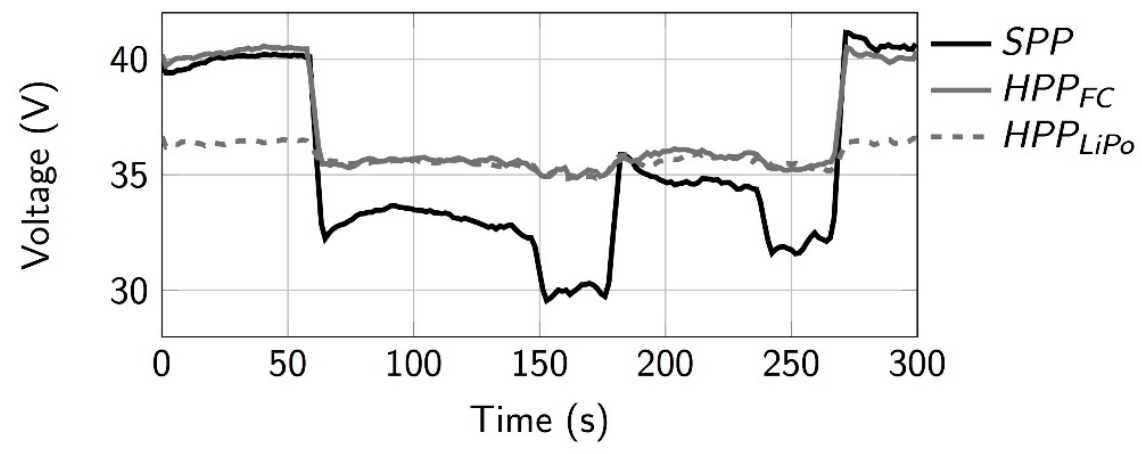

a)

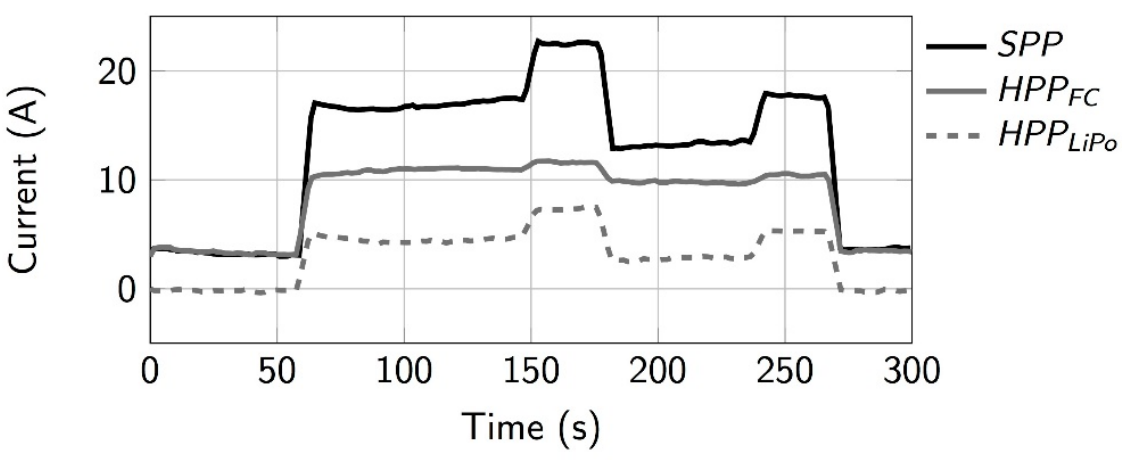

b)

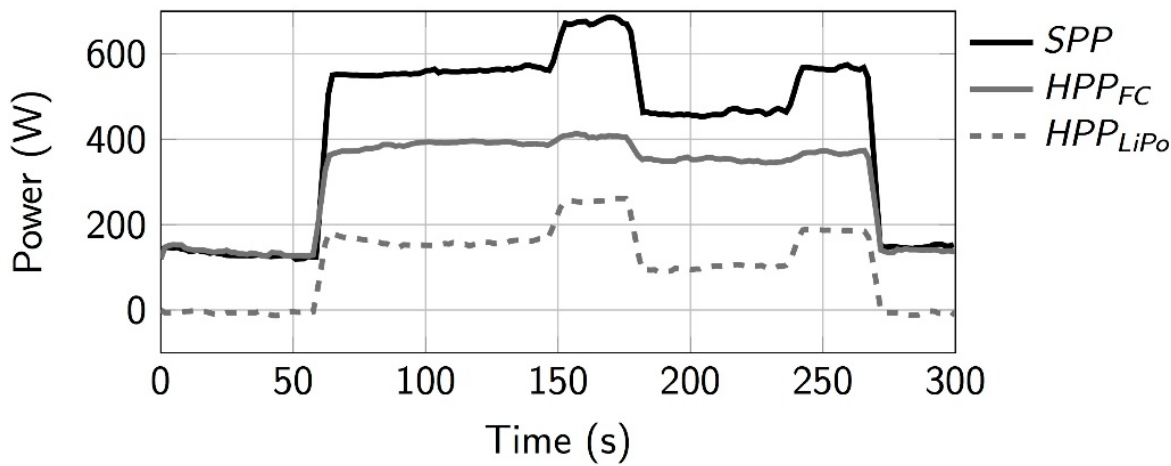

c)

Figure 6: Performance curves of the voltage (a), current (b) and power (c) for the different powerplants

In the case of the p-HPP, the power demanded by the electronic load at the DC bus (see Fig. 5) corresponds to the sum of the power delivered by the stack (HPPFC) and the one yielded by the batteries (HPP LiPO $_{\text {O }}$. As it is shown in Fig. 6a), when the power demanded causes the drop of the stack voltage below the open circuit voltage of the batteries $(35.5 \mathrm{~V})$, the current flows 
from the LiPo batteries to the DC bus (Fig. 6b). Contrary to the SPP, it is observed that the presence of LiPo batteries in this configuration smooths out the sharp peaks of the current curve of the HT-PEMFC, in a similar way as the role played by capacitors in other hybrid power plants $[14,15]$. In the second peak of demand (when $t>150 \mathrm{~s}$ ), the LiPo batteries absorb the additional power increase, due to their fast dynamic response and low Ohmic losses. For these operational points, the power delivered by the HT-PEMFC is saturated, and it is not possible to increase the current supplied, unless the voltage at the DC bus drops, i.e. when the LiPo batteries are discharged. The power curves of Fig. 6 c) show a similar performance than that of the current in Fig. 6b). It should be noted that the total power measured at the DC bus is $5 \%$ lower than the sum of the individual power values supplied by the two power sources, due to losses in the diodes. However, these are even lower than the losses inherent to the switching elements required to regulate the delivered power by active hybrid control systems formed by DC/DC converters.

\subsection{Long-term test}

It was calculated that if the UAV ascends at a constant power, the flight duration required to reach the target altitude $(10,000 \mathrm{~m})$ is more than $1 \mathrm{~h} \mathrm{[22].} \mathrm{To} \mathrm{validate} \mathrm{the} \mathrm{performance} \mathrm{of} \mathrm{the}$ p-HPP, a long-term test is carried out considering three consecutive stages: cruise flight at sea level where the power is supplied by the HT-PEMFC (s1), ascent flight in hybrid mode (s2), and ascent flight only with the stack (s3), once the LiPo batteries are discharged. As in the other tests, the dynamic electronic load was used to simulate the propulsion stage (electric motor and its electronics, transmission, and propeller). However, contrary to the automatic operating mode of the p-HPP in both the steady state and the dynamic performance tests, in the longterm test the point when the LiPo batteries start supplying power to the main DC bus is externally triggered. In the real flight situation, the trigger signal will be included in the UAV autopilot commander. The power demanded at the DC bus for each stage is shown in Table 1. The extent of each stage (s1, s2 and s3) is indicated in Figs. 7a), b) and c) by vertical lines. As before, voltage and current curves are plotted in Figs. 7a) and 7b), respectively, while the power performance is depicted in Fig. $7 \mathrm{c}$ ). The test starts with the cruise stage at sea level (s1), and lasts until minute 11, approximately. Two different phases are clearly identified. The first, and longest, one corresponds to the cruise flight where a constant power of $242 \mathrm{~W}$ is supplied to the DC bus by the HT-PEMFC. The actual power produced by the stack is slightly higher (255 W), as discussed before (see Fig. 7c). The second one is a sharp increase in the 
power generated by the stack rising up to $450 \mathrm{~W}$, which agrees with the mean between the sea level cruise power and the value corresponding to the ascending flight at constant power $(618 \mathrm{~W})$. The objective of this second phase is to prepare the UAV control and maneuver elements (ailerons at the wings, and elevator and rudder at the tail) for the mechanical efforts of the ascending flight. In addition, the increase in the current produced by the stack shortens the time required to reach its optimum working temperature $\left(160^{\circ} \mathrm{C}\right)$.

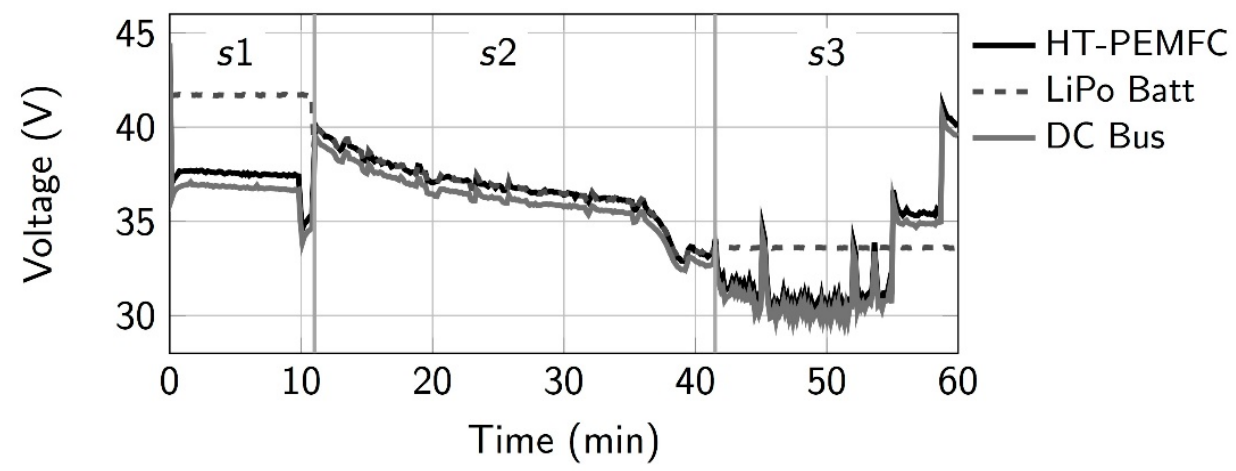

a)

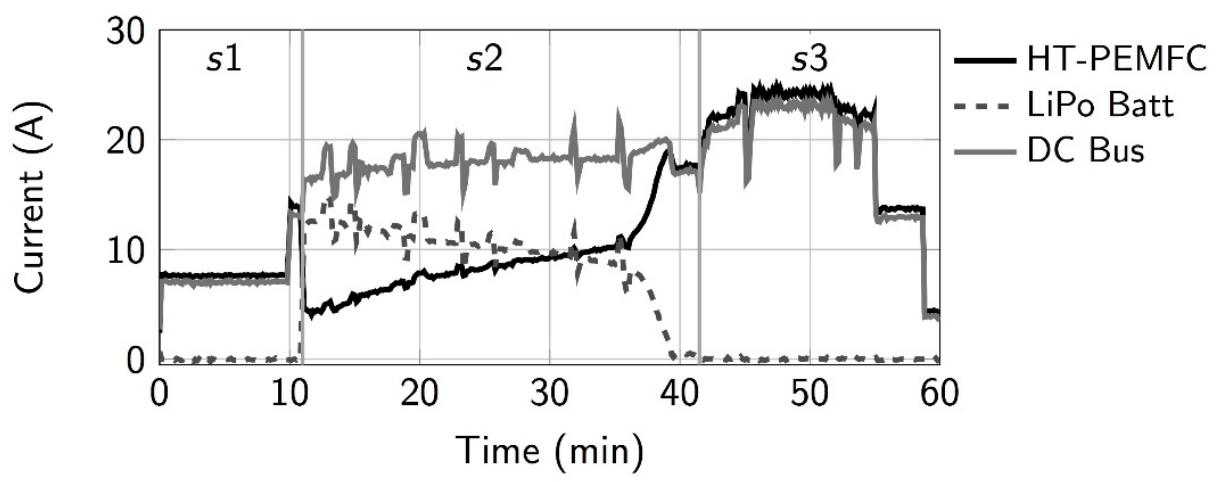

b)

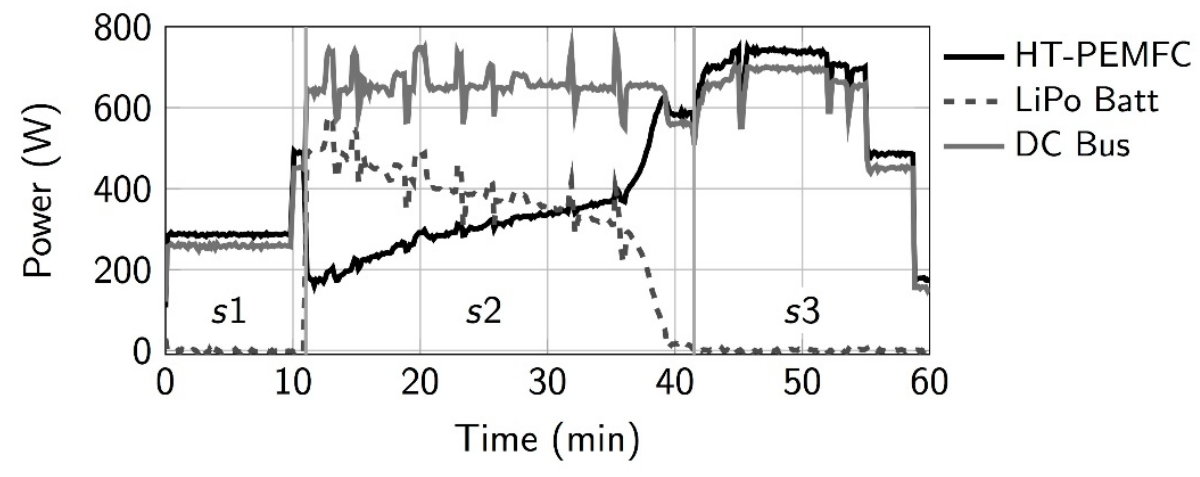

c)

Figure 7: Performance curves of the powerplants during the test: (a) voltage, (b) current, and (c) power

The second stage of the test (s2) is performed with the powerplant working in passive hybrid 
mode. One of the aims of this stage is to discharge the LiPo batteries efficiently. As soon as the acceleration command is applied (in this case modeled by the final increase to $618 \mathrm{~W}$ in the power demanded to the DC bus by the dynamic electronic load), the batteries are simultaneously switched on. To test the robustness of the system, random perturbations of $\pm 15 \%$ over the average demanded power are superposed. These disturbances simulate what can happen on a real flight that tries to keep the ascent rate as stable as possible under harsh flight conditions. As can be observed in both current (Fig. 7b) and power (Fig. 7c) plots, these disturbances are almost fully absorbed in the second stage (s2) by the LiPo batteries (dotted line), while the curve corresponding to the HT-PEMFC stack (solid black line) shows an almost constant increase. A similar result was obtained by Verstraete and co-workers [29] studying the response to dynamic load changes of an active powerplant formed by an Aerostack commercially available stack and three different batteries. An important feature of stage $s 2$ is the coupling of the voltages of the two power sources, which follow the same curve except for small differences due to losses in diodes and cables (Fig. 7a). The total current measured at the $D C$ bus is $4.6 \%$ less than the sum of those yielded by the individual power sources, because part of the current from the HT-PEMFC is used to power its ancillary systems. In Fig. 7b) an inversion in the level of the current supplied by both the stack and the LiPo batteries can be observed close to the minute 32 . This performance indicates that, from this point, the source that mainly controls the power delivered to the DC bus, changes from the batteries to the HTPEMFC (see Fig. 7c). Stage $s 2$ finishes when the charge of the batteries decreases to the minimum established level. This value is not the absolute discharge limit since it is intended to retain part of the stored energy, in order to power the auxiliary systems in the event of a drastic failure of the HT-PEMFC during the rest of the flight. In LiPo batteries, the maximum discharge level is $3 \mathrm{~V}$ per cell, totaling $30 \mathrm{~V}$ for the 10S1P battery. To this end, the minimum battery voltage is set to $33 \mathrm{~V}$, below which the power supplied by the LiPo batteries is stopped.

To estimate the charge of the batteries based on the measured voltage is not accurate, because the actual remaining charge is largely influenced by the discharge strategy used. The higher the discharge current, the larger the power lost due to Joule effect. Considering that the sampling frequency is $9.8 \mathrm{kHz}$, in order to avoid estimation errors or sudden overloads, the configuration of the control system initiates a safe switch-off procedure of the LiPo batteries when the last 100,000 samples (i.e., for a measuring time greater than $10.2 \mathrm{~s}$ ) the voltage measured is below the minimum set voltage. Once the voltage of the batteries is close to the established limit (33 V), the control system momentarily decreases the demanded power, 
causing that the stack voltage to become higher than that supplied by the batteries. At this operating point, it is the stack which mainly delivers the power demanded by the DC bus. The power demanded to the batteries is reduced, decreasing both current and voltage simultaneously. Once the current is set to zero, the diode stops electrical conduction and the electric circuit opens. It is important to note that even when the power demanded by the electronic load (DC motor in the UAV) is momentarily reduced, the actual (measured) power produced by the hybrid powerplant is $592 \mathrm{~W}$, which is always higher than the one needed to keep the UAV flying at a velocity above the stall (minimum) one $\left(24.2 \mathrm{~m} \mathrm{~s}^{-1}\right)$ at the given altitude. It is only $278 \mathrm{~W}$, what means that there is an excess of power around 53\% (314 W). The UAV would climb at a low ascent rate during this time, but the mission would never be jeopardized, even if the aircraft is subjected to strong lateral wind gusts or headwind.

The last stage of the test $(s 3)$ starts when the LiPo batteries are switched off and the total power demanded by the propeller is supplied by the HT-PEMFC. During this stage, the power control is performed monitoring the critical operating parameters of the stack, i.e. the minimum safe voltage $(20 \mathrm{~V})$ and the working temperature. It is important to note that in this stage $(s 3)$, the produced random perturbations induced by the dynamic electronic load are always negative because it is considered that the HT-PEMFC is working at the upper power limit. The increase in the power demanded to the stack and, consequently, in the generated current, results in an increase in the water produced by chemical reaction, in this case in vapor phase. During operation in hybrid mode, this problem is solved because the voltage of the stack is limited by the LiPo batteries. However, when the stack has to supply all the power, the current produced by the stack is higher, and the water vapor produced by chemical reaction is increased. Even when it is easily managed, it is accumulated inside the stack when working at dead-end mode causing ripples on the voltage curve (see Fig. 7a) in s3). It is under this operating regime when the purging time of the two reactant gases must be optimized.

To this end, several test were performed in order to optimize the frequency and opening time (duty cycle) of the solenoid valves used to purge both anode and cathode gas circulation circuits. When working in dead-end mode, purges contribute to eliminate the accumulated impurities (liquid and gaseous) improving the stack performance [30-33]. In Fig. 8, a zoom of the voltage curve between minutes 46 to 48 is depicted, in order to better discuss the effect of the gas purges on the stack performance. The "saw-tooth" shape of the voltage performance curve is due to the rise in concentration losses due to the accumulation of water vapor and nitrogen when working in dead-end mode, in a similar way to what occurs in low- 
temperature PEM fuel cells when liquid water floods some zones of the stack. Therefore, the diffusion of the reactant gases to the catalytic layers is limited, decreasing the total voltage of the stack in the period between two consecutive purges.

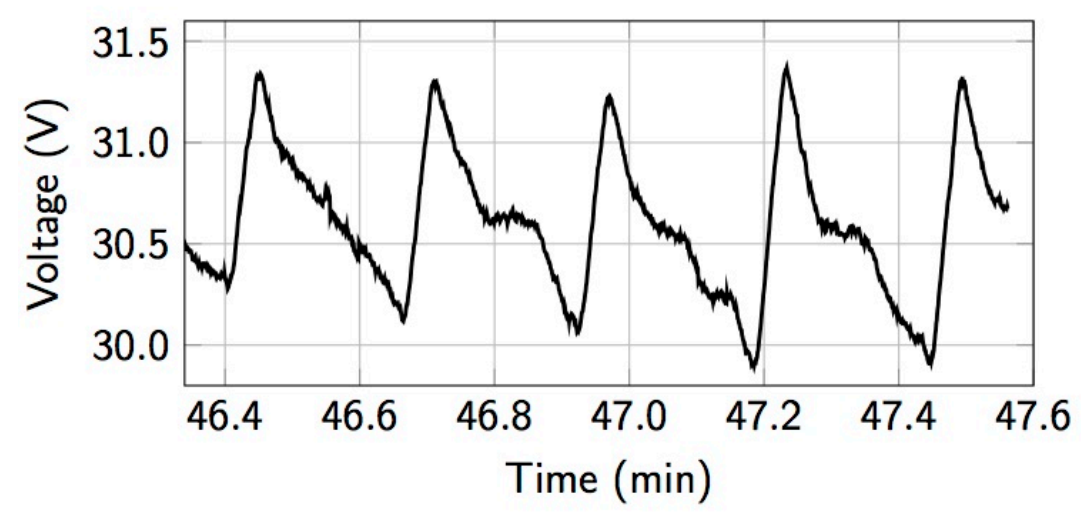

Figure 8: Zoom-in of the fuel cell voltage during the purges performed between minutes 46 to 48 in stage s3

With the results obtained at the preliminary tests, it was verified that the optimum frequency for $\mathrm{H}_{2}$ purges is fixed at $0.05 \mathrm{~Hz}$, every $20 \mathrm{~s}$, but the duty cycle of the valve should vary as a function of the generated current. So, it changes from $80 \mathrm{~ms}$ at low power loads, up to about $250 \mathrm{~ms}$ at the maximum power. This result indicates that water vapor is transported from cathode to anode by back-diffusion, contaminating the hydrogen at the anode side. For the oxygen, it was checked that it is necessary to increase the frequency between purges to $0.1 \mathrm{~Hz}$ (every $10 \mathrm{~s}$ ) with the same duty cycle strategy, due to the above commented increase in concentration losses caused by the amount of water vapor produced in the cathode side. It is also important to note the difference between the voltage response after the first purge and the next ones. In the first one, the voltage drops continuously, while in the rest there is a zone in which the voltage reaches a constant value. This demonstrates the effectiveness of the purges, because the diffusion of the gases towards the catalyst layers is improved, increasing the reaction rate. The purge is stopped when the difference of the measured voltages before and after each purge is less than 5\%. Finally, it was found that once the purge procedure finished, the HT-PEMFC resumed its optimum electrical performance.

An important point that should also be discussed is the amount of reactant gases (hydrogen and oxygen) needed to perform the mission for the two powerplants, including the actual mass of gases wasted in the purges. In the analysis, the same flight range ( 1 hour) has been considered. In the case of the P-HPP the consumption is estimated according to the power (and current) demanded in the long-term test. In contrast, for the SPP, it is considered that the 
ascent flight is performed at constant power (686.3 $\mathrm{W}$ from the HT-PEMFC) for the last 50 minutes, because the first 10 minutes correspond to the cruise at sea-level which is identical to the one in the long-term test for the p-HPP. Time and frequency of the purges have been considered as previously discussed, according to the intensity of the current generated by the stack in both ascending flights. To meet the weight restrictions established by the application, the GSS is formed by two Luxfer type IV cylinders, with a water volume of 4.7 I for hydrogen and 2 I for oxygen. Considering that the amount of gases that can be shipped in the GSS at 300 bar is $89.71 \mathrm{~g}$ of hydrogen and $717.58 \mathrm{~g}$ of oxygen, it was verified that $16.85 \mathrm{~g}$ and $80.84 \mathrm{~g}$ of hydrogen and oxygen, respectively are still remaining when the UAV reaches 10,000 $\mathrm{m}$ for the p-HPP. However, in calculations performed for the SPP, it was found that the target height cannot be reached because an extra mass of $33.55 \mathrm{~g}$ of hydrogen and $269.13 \mathrm{~g}$ of oxygen is still needed. This again demonstrates the higher efficiency of the p-HPP.

Despite the significant results obtained in the experiments performed in the present research, there are still some limitations and improvements of the hybrid powerplant that must be discussed. On the one hand, the test bench results should be verified on an actual flight. Important efforts are being made with different UAV manufacturing companies in order to find an aircraft with the appropriate dimensions where the p-HPP could be mounted and tested. On the other hand, the control system of the p-HPP should be optimized to achieve its optimum performance. The definitive control algorithms for the different operation processes (supply of reactant gases, flight strategy, use of power sources, purge timing, etc.) will be properly integrated into the real aircraft autopilot commander.

\section{Conclusions}

In the present research, it is demonstrated that the hybridization of a HT-PEMFC with LiPo batteries in powerplants with passive control systems can enlarge the useful lifetime of the stack, because the voltage at the DC bus is controlled by the battery when a high power is demanded. In the steady state test, it is verified that the power delivered to the DC bus for the p-HPP is close to $1 \mathrm{~kW}$, with an efficiency of the stack of $44.3 \%$. On the contrary, for the SPP the maximum power generated by the HT-PEMFC is limited to $800 \mathrm{~W}$ with an efficiency of only $36.4 \%$. A test performed to study the dynamic behavior of the $\mathrm{p}-\mathrm{HPP}$, demonstrated that the presence of LiPo batteries in this configuration smooths out the sharp peaks of the current curve of the HT-PEMFC, reducing the degradation phenomena that they can induce.

With the long-term test, where three different flight situations are simulated, it was 
demonstrated the robustness of the control system, which is able to efficiently deliver the energy demanded in the bus during the ascent flight even when $\pm 15 \%$ random disturbances of the ascending power are considered. It is also found that during the ascending flight stage, in which the powerplant operates in hybrid mode, the contamination of both hydrogen and oxygen by the increase of the water vapor accumulated inside the stack is reduced because the current produced by the stack is limited by the LiPo batteries. However, the importance of the purges is evidenced once the LiPo batteries are switched off, and the full power is supplied by the stack. The accumulation of water vapor causes ripples on the voltage curve, and it is then when the two reactant gases have to be purged. The frequency and duration of the purges has been optimized as a function of the power generated. Their effectiveness is determined considering the difference of the overall stack voltage measured before and after each purge. It has been found that once the purge procedure finishes, the HT-PEMFC resumes its optimum electrical performance. Finally, the efficiency of the p-HPP has been demonstrated. It has been shown that, contrary to what happens with the SPP, the p-HPP allows reaching the target height with the gas storage system considered in the application.

\section{Acknowledgements}

This work has been partially funded by the Secretariat of State for Research of the Spanish Ministry of Economy and Competitiveness under projects ENE2012-38642-C02-01/CON and DPI2015-69286-C3-1-R. Support of the Regional Government of Aragon to the Experimental Fluid Dynamics Research Group (T03) of LIFTEC is also acknowledged.

\section{References}

[1] O. González-Espasandín, T. J. Leo, E. Navarro-Arévalo, Fuel cells: a real option for unmanned aerial vehicles propulsion, The Scientific World J., vol. 2014 (2014) 1-12.

[2] R. Austin, Unmanned aircraft systems: UAVs design, development and deployment, first ed. John Wiley \& Sons, 2010

[3] V. P. McConnell, Military UAVs claiming the skies with fuel cell power, Fuel Cells Bulletin, vol. 2007 (2007) 12-15

[4] T. J. Gross, A. J. Poche Jr, and K. C. Ennis, Beyond demonstration: the role of fuel cells in DoD's energy strategy, DTIC Document, Tech. Rep., 2011

[5] M. Ehsani, Y. Gao, S.E. Gay, A. Emadi, Modern electric, hybrid electric, and fuel cell vehicles: fundamentals, theory, and design, first ed. CRC press, 2004 
[6] J. Hung, L. F. Gonzalez, On parallel hybrid-electric propulsion system for unmanned aerial vehicles, Prog. Aerospace Sc., vol. 51 (2012) 1-17

[7] Y.-S. Chen, S.-M. Lin, B.-S. Hong, Experimental study on a passive fuel cell/battery hybrid power system, Energies, vol. 6 (2013) 6413-6422

[8] R. K. Ahluwalia, X. Wang, Direct hydrogen fuel cell systems for hybrid vehicles, J. Power Sources, vol. 139 (2005) 152-164

[9] J. Bernard, S. Delprat, F. N. Buchi, T. M. Guerra, Fuel-cell hybrid powertrain: Toward minimization of hydrogen consumption, IEEE Trans. Vehicular Tech., vol. 58 (2009) 3168-3176

[10] L. Gao, Z. Jiang, R. A. Dougal, An actively controlled fuel cell/battery hybrid to meet pulsed power demands, J. Power Sources, vol. 130 (2004) 202-207

[11] M. Blackwelder, R. Dougal, Power coordination in a fuel cell-battery hybrid power source using commercial power controller circuits, J. Power Sources, vol. 134 (2004) 139-147

[12] Z. Jiang, L. Gao, M. J. Blackwelder, and R. A. Dougal, Design and experimental tests of control strategies for active hybrid fuel cell/battery power sources, J. Power Sources, vol. 130 (2004) 163-171

[13] F. Büchi, G. Paganelli, P. Dietrich, D. Laurent, A. Tsukada, P. Varenne, A. Delfino, R. Kötz, S. Freunberger, P.-A. Magne et al., Consumption and efficiency of a passenger car with a hydrogen/oxygen PEMFC based hybrid electric drivetrain, Fuel Cells, vol. 7 (2007) 329335

[14] P. Thounthong, S. Rael, B. Davat, Energy management of fuel cell/battery/supercapacitor hybrid power source for vehicle applications, J. Power Sources, vol. 193 (2009) 376-385

[15] A. Sripakagorn and N. Limwuthigraijirat, Experimental assessment of fuel cell/supercapacitor hybrid system for scooters, Int. J. Hydrogen Energy, vol. 34 (2009) $6036-6044$

[16] Y. Tang, W. Yuan, M. Pan, Z. Wan, Experimental investigation on the dynamic performance of a hybrid PEM fuel cell/battery system for lightweight electric vehicle application, Appl. Energy, vol. 88 (2011) 68-76

[17] A. Nishizawa, J. Kallo, O. Garrot, J. Weiss-Ungethüm, Fuel cell and li-ion battery direct hybridization system for aircraft applications, J. Power Sources, vol. 222 (2013) 294-300 
[18] J. Bernard, M. Hofer, U. Hannesen, A. Toth, A. Tsukada, F. N. Büchi, P. Dietrich, Fuel cell/battery passive hybrid power source for electric powertrains, J. Power Sources, vol. 196 (2011) 5867-5872

[19] D. Verstraete, A. Gong, D. D.-C. Lu, J. L. Palmer, Experimental investigation of the role of the battery in the aerostack hybrid, fuel-cell-based propulsion system for small unmanned aircraft systems, Int. J. Hydrogen Energy, vol. 40 (2015) 1598-1606

[20] K. E. Aifantis, S. A. Hackney, and R. V. Kumar, High energy density lithium batteries: materials, engineering, applications, first ed., WILEY-VCH Verlag GmbH \& Co. KGaA, 2010

[21] B. Scrosati, J. Garche, Lithium batteries: Status, prospects and future, J. Power Sources, vol. 195 (2010) 2419-2430

[22] J. Renau, A. Lozano, J. Barroso, J. Miralles, J. Martin, f. Sanchez, F. Barreras, Use of fuel cell stacks to achieve high altitudes in light unmanned aerial vehicles. Int. J. Hydrogen Energy (2015) 40, pp. 14573-14583

[23] J. Barroso, J. Renau, A. Lozano, J. Miralles, J. Martin, F. Sanchez, F. Barreras, Experimental determination of the heat transfer coefficient for the optimal design of the cooling system of a PEM fuel cell placed inside the fuselage of an UAV, Appl. Therm. Eng., vol. 89 (2015) 1-10

[24] J. Renau, J. Barroso, A. Lozano, A. Nueno, F. Sanchez, J. Martin, F. Barreras, Design and manufacture of a high-temperature PEMFC and its cooling system to power a lightweight UAV for a high altitude mission, Int. J. Hydrogen Energy, vol. 41 (2016) 19702-19712

[25] C. Henskel, Celtec-P Membrane Electrode Assembly, Technical Information Brochure, DBASF The Chemical Company, Frankfurt, August 2011

[26] F. Barreras, A. Lozano, V. Roda, J. Barroso, J. Martín, Optimal design and operational tests of a high-temperature PEM fuel cell for a combined heat and power unit, Int. J. Hydrogen Energy, vol. 39 (2014) 5388-5398

[27] LRP electronic GmbH. http://www.Irp.cc/en/product/Irp-8100-112-1s-110c55c-37-lipo112-competition-car-line-hardcase/, 2016 (accessed 12.15.16)

[28] M. Dou, M. Hou, D. Liang, Q. Shen, H. Zhang, W. Lu, Z. Shao, B. Yi, Behaviors of proton exchange membrane fuel cells under oxidant starvation, J. Power Sources, vol. 196 (2011) 2759-2762 
[29] D. Verstraete, A. Gong, D.D.-C. Lu, J.L. Palmer, Experimental investigation of the role of the battery in the AeroStack hybrid, fuel-cell-based propulsion system for unmanned aircraft systems, Int. J. Hydrogen Energy, vol. 40 (2015) 1598-1606

[30] J. Chen, J.B. Siegel, A.G. Stefanopoulou, J.R. Waldecker, Optimization of purge cycle for dead-ended anode fuel cell operation, Int. J. Hydrogen Energy, vol. 38 (2013) 5092-5105

[31] Q. Meyer, S. Ashton, O. Curnick, T. Reisch, P. Adcock, K. Ronaszegi, J.B. Robinson, D.J.L. Brett, Dead-ended anode polymer electrolyte fuel cell stack operation investigated using electrochemical impedance spectroscopy, off-gas analysis and thermal imaging, J. Power Sources, vol. 254 (2014) 1-9

[32] Q. Meyer, S. Ashton, S. Torija, Ch. Gurney, P. Boillat, M. Cochet, E. Engebretsen, D.P. Finegan, P. Adcock, P. R. Shearing, D.J.L. Brett, Nitrogen blanketing and hydrogen starvation in ded-ended-anode polymer electrolyte fuel cell revealed by hydro-electrothermal analysis, Electrochemical Acta, vol. 203 (2016) 198-205

[33] Y-F. Lin, Y-S Chen, Experimental study on the optimal purge duration of a proton exchange membrane fuel cell with a dead-ended anode, J. Power Sources, vol. 340 (2017) 176-182 